\title{
0
}

O L H A R E S

REVISTA DO DEPARTAMENTO DE EDUCAC̈̈O - UNIFESF

\section{FREIRE, PRESENTE! ESCUTA, DIÁLOGO E HORIZONTALIDADE NA FORMAÇÃO CONTINUADA DE PROFESSORES DE INGLÊS}

\author{
FREIRE, AQUÍi ESCUCHA, DIÁLOGO Y HORIZONTALIDAD EN LA \\ FORMACIÓN CONTINUA DE PROFESORES DE INGLÉS
}

\author{
FREIRE, PRESENT! LISTENING, DIALOGUE AND HORIZONTALITY IN THE \\ CONTINUOUS EDUCATION OF ENGLISH TEACHERS
}

\author{
Lediane Manfé de Souza \\ IFPR/UNIOESTE \\ lediane.souza@ifpr.edu.br \\ Carmen Teresinha Baumgärtner \\ UNIOESTE \\ carmen.baumgartner@unioeste.br
}

\begin{abstract}
Resumo: O presente trabalho é um recorte de uma pesquisa etnográfica de doutorado, realizada em um curso de formação continuada para professores de inglês da Educação Básica, ofertado por uma instituição de ensino técnico e tecnológico do estado do Paraná. Neste estudo, foram investigadas reações e ressignificações do conhecimento local (CANAGARAJAH, 2005; NORTON, 2010) de nove professoras e dois professores de língua inglesa durante sua participação no curso. A análise dos dados apresentada neste artigo foi construída com base na observação participante, notas de campo e vinhetas narrativas, próprias da experiência etnográfica vivenciada por uma das autoras, que também desempenhou o papel de professora-formadora. A partir da concepção freireana do diálogo e da escuta, caracterizada pelo princípio da horizontalidade (FREIRE, 1991), o curso foi pensado para dialogar com os professores e problematizar conhecimentos que levassem à ampliação das possibilidades de trabalho nas aulas de língua inglesa, viabilizando a educação linguística em língua estrangeira/adicional por meio do letramento crítico. Dentre os conhecimentos locais analisados, a própria participação das professoras e professores em cursos de formação continuada mostrou-se passível de ressignificação durante o processo de reflexividade.
\end{abstract}

Palavras-chave: Formação continuada de professores/as de inglês. Diálogo, escuta e horizontalidade. Ressignificação do conhecimento local.

Resumen: El presente trabajo es un recorte de una investigación etnográfica doctoral, desarrollada en un curso de formación continua para profesores de inglês de Educación Básica, ofrecido por una institución de educación técnica y tecnológica del estado de Paraná. En este estudio se investigaron las reacciones y resignificaciones del conocimiento local (CANAGARAJAH, 2005; NORTON, 2010) de nueve profesoras de inglés y dos profesores de inglês durante su participación en el curso. El análisis de datos presentado en este artículo académico se construyó sobre la base de la observación participante, notas de campo y viñetas narrativas, propias de la experiencia etnográfica vivida por uno de los autores, quien también desempeñó el papel de docente-formador. Partiendo de la concepción freireana del diálogo y de escucha, caracterizada por el principio de horizontalidad (FREIRE, 1991), el curso fue diseñado para dialogar con los profesores y discutir conocimientos que llevarían a la expansión de las expansión de las prácticas pedagógicas en las clases de inglés, posibilitando la educación lingüística en lengua extranjera/adicional a través de la literacidad crítica. Entre los saberes locales analizados, la participación de los docentes en los cursos de formación continua se mostró sujeto a resignificación durante el proceso de reflexividad. 
Palabras clave: Formación continua de profesores de inglés. Diálogo, escucha y horizontalidad. Resignificación del conocimiento local.

\begin{abstract}
The present work is an excerpt of an ethnographic doctoral research carried out in a continuing education course for Elementary and High School English teachers, offered by a technical and technological education institution in the state of Paraná. In this study, reactions and resignifications of local knowledge (CANAGARAJAH, 2005; NORTON, 2010) of nine female and two male English language teachers during their participation in the course were investigated. The data analysis presented in this paper was built based on participant observation, field notes and narrative vignettes, typical of the ethnographic experience lived by one of the authors, who also played the role of teacher-educator. Based on the Freirean conception of dialogue and listening, characterized by the principle of horizontality (FREIRE, 1991), the course was designed to dialogue with the teachers and discuss knowledge that would lead to the expansion of practices in English classes, enabling the language education in foreign/additional language through critical literacy. Among the local knowledge analyzed, the participation of teachers in continuing education courses proved to be subject to resignification during the process of reflexivity.
\end{abstract}

Keywords: Continuing English teacher Education. Dialogue, listening and horizontality. Resignification of local knowledge.

\title{
Introdução
}

Partindo do pressuposto de que a língua, por si só, pode tanto empoderar quanto marginalizar ${ }^{1}$, Hawkins e Norton (2009), linguistas alinhadas ao pensamento freireano, evidenciam a importância de uma formação continuada crítica do professor de inglês, o que possibilita chegarmos, consequentemente, a uma educação linguística crítica, que tem suas bases na Linguística Aplicada Crítica, defendida por Rajagopalan (2003) como uma linguística voltada para questões práticas de relevância social e definida por Pennycook (2006. p. 67) como "uma abordagem mutável e dinâmica para questões de linguagem em contextos múltiplos [...".

Norton (2010) ressalta a necessidade de uma educação linguística local, em que professores e alunos desenvolvam aspectos identitários ao ensinar e aprender outra língua. Especificamente em língua estrangeira/adicional², Garcez (2008, p. 52) defende o ponto de vista de que a prática de educação linguística não deve prender-se à busca da proficiência linguística, mas orientar-se pelo que chama de parâmetros de formação de um cidadão "[...] apto ao trânsito nas sociedades complexas contemporâneas e preparado para o

\footnotetext{
$1 \mathrm{Na}$ perspectiva da Educação Linguística (GARCEZ, 2008), entendemos que estes fenômenos estão relacionados à participação dos falantes nas práticas sociais das quais precisam ou querem participar.

${ }^{2} \mathrm{O}$ termo língua adicional vem sendo usado no ensino de línguas para enfatizar "o acréscimo que a disciplina traz a quem se ocupa dela, em adição a outras línguas que o educando já tenha em seu repertório" (SCHLATTER; GARCEZ, 2009, p. 127). Neste estudo, os termos língua estrangeira e língua adicional são usados de modo intercambiável. No entanto, saliento que o termo discutido por Schlatter e Garcez (2009) apresenta-se mais alinhado ao ensino e aprendizagem de línguas com base na educação linguística.
} 
enfrentamento com a diversidade e o trânsito intercultural, ou seja, um cidadão plenamente letrado [...]", capaz de se mover no e com o mundo (FREIRE, 2011b).

Nessa perspectiva educacional, a sala de aula é concebida como um espaço de conflito e transformação da realidade (FREIRE, 2011b). No contexto da pesquisa, os conflitos emergiram das problematizações do curso norteado pelas teorizações do letramento crítico, suscitando constante negociação de sentidos das maneiras de saber compartilhadas pelos participantes da experiência vivida. Do mesmo modo, o trabalho com o letramento crítico em sala de aula torna necessário o reconhecimento do conflito como uma força geradora de significados. Assim sendo, nós, professoras e professores de línguas, temos um papel importante, mas precisamos estar preparados para extrapolar as formas e os conteúdos, e trabalhar em favor da constituição da autonomia de nossos alunos e alunas, o que, segundo Freire (2011a, p. 105, grifos do autor) acontece "enquanto amadurecimento do ser para si, é processo, é vir a ser.".

Na mesma direção, e diante da instabilidade e efemeridade dos acontecimentos nas sociedades contemporâneas, vale dizer que o ensino de qualquer língua estrangeira na escola deve visar à formação integral do aluno, o que inclui o desenvolvimento do senso crítico, da criatividade e a abertura para novos conhecimentos. Assim, chegamos a um propósito no ensino de línguas pertinente a um mundo globalizado, que, cada vez mais, necessita de cidadãos críticos, capazes de compreender suas realidades e capacitados para transformá-las, se for preciso. Esse propósito só poderá ser alcançado quando passarmos a refletir sobre o porquê e para que nós ensinamos línguas (RAJAGOPALAN, 2017, comunicação pessoal) ${ }^{3}$.

Isso nos leva a pensar que, em um momento no qual o entendimento sobre o papel da língua inglesa no mundo, bem como das metodologias para esse ensino continuam a ser questionados e repensados (KUMARAVADIVELU, 2003a), professoras e professores necessitam reexaminar questões que atravessam a sala de aula, a fim de reavaliar suas práticas e decidir se são necessárias mudanças (MANFÉ DE SOUZA, 2014).

Buscando criar oportunidades para tais discussões no campo de ensino de língua inglesa, entre os meses de agosto e dezembro de 2018 foi realizado o curso de extensão "Educação linguística, letramento crítico e interculturalidade: expanding horizons in English classes", em que uma das autoras do presente texto atuou como formadora e, também, desenvolveu sua pesquisa de doutoramento, da qual este artigo provém. $\mathrm{O}$ curso foi

\footnotetext{
${ }^{3}$ Chamamos de comunicação pessoal as discussões realizadas durante o Seminário Avançado "O ensino de línguas como parte integral da política linguística: A necessidade de uma abordagem crítica", ministrado pelo prof. Dr. Kanavilil Rajagopalan, no Programa de Pós Graduação em Linguagem e Sociedade da Unioeste.
} 
ancorado no entendimento de educação linguística como um conjunto de fatores socioculturais que fazem parte da vida dos estudantes e que podem contribuir para o desenvolvimento de seu conhecimento sobre línguas (materna ou estrangeira) e linguagem de um modo geral (BAGNO; RANGEL, 2005). Tal ponto de vista alinha-se à abordagem intercultural, que, segundo Corbett (2003), deve considerar a construção de identidades, o entendimento e a mediação das diferenças culturais de modo que o aprendiz não desvalorize sua cultura e se abra para outras perspectivas.

O diálogo desses construtos com o letramento crítico é intrínseco, tendo em vista a criação de oportunidades para a problematização e o questionamento do status quo, bem como a preocupação com os processos de identidade, diferença e construção/negociação de sentidos. Sendo assim, o curso de formação continuada buscou as problematizações do letramento crítico, não como um método de ensino, mas como algo mais abrangente, uma epistemologia "de natureza filosófico-educacional-cultural" (MONTE MÓR, 2018a, p.322), enfatizando a expansão de perspectivas (MONTE MÓR, 2009, 2011, 2018a) na ampliação da leitura de mundo por meio da construção de sentidos nas dimensões individual, comunitária e global.

Nove professoras e dois professores de inglês da Educação Básica ${ }^{4}$ participaram do curso de 60 horas $^{5}$, ofertado por uma instituição federal de ensino técnico e tecnológico, localizada no centro-sul do estado do Paraná. O curso foi pensado para dialogar com os professores e problematizar conhecimentos que levassem à ampliação das possibilidades de trabalho nas aulas de língua inglesa, viabilizando a educação linguística em língua estrangeira por meio do letramento crítico (MENEZES DE SOUZA, 2011; MONTE MÓR, 2018).

Nesse contexto, foram investigadas reações e ressignificações do conhecimento local (CANAGARAJAH, 2005; NORTON, 2010) de professoras e professores de língua inglesa durante a participação no curso de formação continuada, entendendo o conhecimento local como aquele "vinculado ao contexto, específico da comunidade, e não sistemático porque é gerado a partir da prática social na vida cotidiana." (CANAGAJARAH, 2005, p. 5). Utilizamos o termo "reação" para fazer referência a toda e qualquer manifestação dos/das participantes da pesquisa às problematizações do curso orientado pelo letramento crítico. Em se tratando de uma pesquisa etnográfica, as "reações" são vistas, analisadas e interpretadas como encontros culturais circunstanciados.

\footnotetext{
${ }^{4}$ A adesão dos professores ao curso foi voluntária, assim como sua participação nesta pesquisa.

5 Das 60 horas do curso, 40 horas foram realizadas presencialmente e 20 horas foram destinadas às leituras prévias e à elaboração de um plano de ensino na perspectiva do letramento crítico.
} 
A pesquisa à qual este artigo integra, situa-se no campo da Linguística Aplicada e busca discutir e interpretar, por meio das lentes culturais da pesquisa etnográfica (ERICKSON, 1984), aspectos contextuais da formação continuada de professores de inglês da Educação Básica a partir da perspectiva freireana da escuta e do diálogo (FREIRE; SHOR, 1987; FREIRE, 1991).

\section{Formação continuada: para quê?}

Ninguém educa ninguém, ninguém se educa a si mesmo, os homens se educam entre si, mediatizados pelo mundo. (FREIRE, 2011b, p. 95).

Com o propósito de responder à pergunta do título, buscamos sentidos nos ideais de Paulo Freire, que implicam atitudes de escuta, solidariedade e humanização, percebendo-se a si próprios e ao outro nas relações com o mundo, considerando que "ao mesmo tempo em que se aprende a escutar, é preciso aprender a se ouvir escutando" (MENEZES DE SOUZA, 2011, p. 132, grifo do autor). Dessa forma, o processo da nossa formação como educadores, que inclui também a formação de formadores, pressupõe estar disposto a relacionar-se com outras professoras e professores, com saberes e práticas que se assemelham ou se distanciam, que se atraem ou se repelem. Escutar, ao modo freireano, não significa acomodar-se, mas permitir encontros e mover dentro de si inquietações a partir das implicações com o outro.

Essa foi a postura pretendida pela pesquisadora e formadora em formação no contexto do curso, que possibilitou aliar a necessidade local de formação continuada a uma forma de ouvir as professoras e os professores, de estar, estudar e refletir com eles. A partir de experiências anteriores (a exemplo de MANFÉ DE SOUZA, 2014), a formação continuada é aqui discutida como um espaço de interlocução entre professores e professores-formadores. Nesse espaço, pretende-se que o conhecimento acadêmico seja impregnado do conhecimento local, no sentido freireano de práxis, "o lugar onde teoria e prática se juntam para criar ações que levam a mudanças sociais e políticas." 6 (HAWKINS; NORTON, 2009, p. 31). Essa ideia tem sido utilizada e reinterpretada por pesquisadores no mundo todo, que entendem a necessidade da integração entre "teoria e prática nos interesses de mudança social e educacional." 7 (HAWKINS; NORTON, 2009, p. 36).

\footnotetext{
6 Texto original: "[...] the site where theory and practice come together to create action that leads to social and political change."

7 Texto original: "[...] theory and practice in the interests of educational and social change."
} 
Culturalmente, em diferentes contextos, o conhecimento da academia carrega uma validação intrínseca, capaz de abafar, de sobrepor-se a outros tipos de conhecimento, principalmente em se tratando de conhecimentos locais, que ainda são tratados de forma pejorativa e inferior em muitos círculos (CANAGARAJAH, 2005). Na formação continuada de professores, mesmo sem ser imposta, a ideia de que o formador detém o conhecimento e tem respostas prontas para os desafios de ensinar é validada por uma espécie de autoridade acadêmica, uma determinação cultural que paira na relação professor-formador, na qual o conhecimento local costuma ficar em segundo plano, em relação ao conhecimento acadêmico representado pelo formador.

Do mesmo modo, na "relação entre pesquisadores e professores, o habitual tem sido as vozes dos professores subordinarem-se às vozes dos pesquisadores." (COX; ASSISPETERSON, 2001, p. 28-29). Nesse contexto, a diferenciação entre teoria e prática, que reforça a subordinação de professores a formadores e a pesquisadores, é representativa da relação global x local. O status dos professores como aqueles que põem em prática, que executam o que a academia pensa, coloca-os em segundo plano, como meros implementadores, "ao invés de agentes no processo da teoria, da construção, do planejamento de currículo e do desenvolvimento de política de línguas" (CLARKE, 1994, p. 10), desacreditando-os da possibilidade da pesquisa e da reflexão. Sobre isso, Pennycook (1994, p. 299) nos lembra que uma visão de ensino problematizadora

[...] busca se opor à maneira que os professores são frequentemente posicionados nos dias de hoje como técnicos de sala de aula contratados para passar adiante um conjunto de conhecimentos, e oferece uma versão de ensino que remova a divisão da prática teórica e enfatize a importância de trabalhar em direção à transformação social ${ }^{8}$.

Embora saibamos que toda a prática seja movida por algum saber teórico, que nossa concepção de mundo seja sempre informada por nossas atitudes, orientando nossas escolhas (JORDÃO, 2006), convém lembrar o que afirma Rajagopalan $(2006$, p. 165) a respeito da crença de que a teoria seja "precondição para qualquer tipo de prática", crença esta que, segundo o autor, já está ultrapassada, tendo em vista que "elucubrações teóricas que não contemplem sua aplicabilidade na prática não valem nada.”. Do mesmo modo, não é possível ignorar o fato de que, mergulhados na realidade da Educação Básica brasileira, professoras e professores não tão têm tempo, nem energia para pensar suas práticas de forma sistematizada ou buscar teorias para "comprovar" as vivências em sala de aula. Por

\footnotetext{
8 Texto original: "[...] aims to oppose the way teachers are today often positioned as classroom technicians employed to pass on a body of knowledge, and its place offers a version of teaching that removes the theory practice divide and stresses the significance of working towards social transformation."
} 
meio da problematização, o que se propõe no contexto da formação continuada crítica é inverter essa lógica e pensar a educação a partir dos contextos imediatos dos/das participantes. Assim, extingue-se a ideia de que possa existir um modelo de formação continuada eficaz em qualquer realidade. Subentendendo-se que "a prática crítica é situada, responsiva e contextual, fica claro que a busca de um modelo único para a formação crítica de professores de línguas é inadequada." 9 (HAWKINS; NORTON, 2009, p. 37).

Portanto, quando se fala em formação continuada, muitas são as abordagens possíveis e os entendimentos sobre o que seja formar professores que já estão em serviço. Neste estudo em particular, as discussões sobre formação continuada tomam por base a concepção freireana do diálogo e da escuta (FREIRE; SHOR, 1987; FREIRE, 1991), sendo um, pré-condição para a existência do outro. São atitudes que se complementam, pois estar aberto ao diálogo significa, ao mesmo tempo, estar disponível à escuta e à compreensão do contexto em uma atitude responsiva, na qual dialogar "implica responsabilidade, direcionamento, determinação, disciplina, objetivos." (FREIRE; SHOR, 1987, p. 123).

A pedagogia de Freire ensina que a escuta é o fundamento do diálogo: ao escutar se aprende a falar com o outro, não para o outro e nem sobre o outro, "um reconhecimento do direito à fala e à escuta. É o exercício da prática dialógica." (SANTIAGO; BATISTA NETO, 2011, p. 12). Para Freire (1991, p. 135):

\footnotetext{
Escutar é obviamente algo que vai mais além da possibilidade auditiva de cada um. Escutar, no sentido aqui discutido, significa a disponibilidade permanente por parte do sujeito que escuta para a abertura à fala do outro, ao gesto do outro, às diferenças do outro. Isto não quer dizer, evidentemente, que escutar exija de quem realmente escuta sua redução ao outro que fala.
}

Na formação de professores, a escuta e o diálogo também podem ser pensados como uma aprendizagem recíproca, que acontece entre formadores e professores (SANTIAGO; BATISTA NETO, 2011). Pode parecer algo natural, mas muitos modelos de formação desconsideram essa prática, justamente por verem os professores apenas como implementadores de teorias, ao invés de agentes capazes de participar do processo de construção e de desenvolvimento de propostas para a sala de aula (CLARKE, 1994).

Do ponto de vista da formação continuada aqui discutida, a relação dialógica se caracteriza pelo princípio de horizontalidade (FREIRE, 1991), na qual professores são vistos como parceiros capazes de pensar e de colaborar na construção de alternativas viáveis para suas realidades contingenciais. Seguindo essa concepção formadora, Jordão (2017, p.

\footnotetext{
${ }^{9}$ Texto original: "[...] critical practice is situated, responsive and contextual, it is clear that the pursuit of a onesize-fits-model of critical language teacher education is inadequate."
} 
192) reafirma a necessidade de que essas ações se deem na dimensão da práxis, "partindo do pressuposto de que teoria e prática são integradas, e de que formadores e professores (afinal, somos todos professores, não é?) juntos podem melhorar o ensino-aprendizagem nas escolas - e fora delas.".

Propor-se a ouvir os professores é dialogar com eles, criando oportunidades de reavaliação de práticas culturais e possibilitando a problematização dos conhecimentos locais, gerados nas práticas sociais da vida cotidiana (CANAGARAJAH, 2005). Nesse sentido, outro ponto levantado por Freire e Shor (1987) é que o diálogo não pode representar uma forma de manipulação ou simples obtenção de resultados, mas, sim, ser visto como parte integrante da própria natureza histórica dos seres humanos. Os autores concordam que

[...] o diálogo é uma espécie de postura necessária, na medida em que os seres humanos se transformam cada vez mais em seres criticamente comunicativos. $O$ diálogo é o momento em que os humanos se encontram para refletir sobre sua realidade tal como a fazem e refazem [...]. Através do diálogo, refletindo juntos sobre o que sabemos, podemos, a seguir, atuar criticamente para transformar a realidade. [...] O diálogo sela o relacionamento entre sujeitos cognitivos; podemos, a seguir, atuar criticamente para transformar a realidade. [...] Eu acrescentaria que o diálogo valida ou invalida as relações sociais das pessoas envolvidas nessa comunicação. [...] O diálogo libertador é uma comunicação democrática, que invalida a dominação [...] ao afirmar a liberdade dos participantes de refazer a cultura. (FREIRE; SHOR, 1987, p. 123).

Seguindo essa apreciação, a prática pedagógica assume-se transformadora, necessitando de um pensar contínuo e permanente, tendo em vista a limitação e as constantes - e cada vez mais rápidas - mudanças humanas e sociais. A isso, Santiago e Batista Neto (2011, p. 8) acrescentam que a teoria freireana coloca algumas questões importantes para "[...] a formação de professores, de modo a que ela se faça a partir do conhecimento e da crítica do existente, problematizadora do existente, contextualizada, porque historicamente datada e localizada, e transformadora.".

Sob essa ótica, como prática problematizadora situada historicamente, a teoria freireana dialoga com os anseios do curso de formação continuada, locus desta pesquisa, por se tratar de uma oportunidade de problematização da realidade. Assim, tanto a realização do curso de formação continuada quanto a pesquisa naquele contexto tomaram por base uma prática docente crítica "que envolve o movimento dinâmico, dialético entre o fazer e o pensar sobre o fazer" (FREIRE, 2011a, p. 39) e, por consequência, uma abordagem crítica no ensino de línguas estrangeiras na escola. Dentre os muitos modos de ser crítico e seus diversos domínios, nesta pesquisa, o uso do termo refere-se ao que Pennycook (2006, p. 67) chamou de "prática pós-moderna problematizadora", por meio da 
qual visões binárias/dicotômicas podem ser questionadas. Partindo desse pensamento, a educação linguística torna-se terreno fértil para o desenvolvimento da criticidade através da constante problematização e questionamento, contribuindo na construção de um contradiscurso a respeito do pensamento homogeinezador da vida contemporânea (MOITA LOPES, 2005), especialmente no ensino de inglês, que por tanto tempo reforçou apagamentos de individualidades em favor de discursos hegemônicos e homogeneizantes.

Diante desses pressupostos, a entrada no campo de pesquisa foi marcada pela consciência da necessidade de que a pesquisadora assumisse a posição de ouvinte. Com tantos começos possíveis, saber o que motivava as professoras e os professores a estarem ali naquele encontro e nos outros que viriam pareceu necessário, e foi o primeiro questionamento a eles direcionado. Por escrito, o grupo relatou quais eram suas expectativas com relação ao curso. Alguns queriam aprender métodos, outros disseram querer desenvolver-se mais na língua inglesa e profissionalizar-se, queriam aprender técnicas inovadoras, estavam ali para ter contato com a universidade, para sair do comodismo, para falar com outros professores, para discutir as angústias e a realidade da sala de aula. Não mencionaram a possibilidade de terem o que ensinar ou de juntos com a formadora terem o que aprender.

Para ilustrar como esse diálogo com as professoras e os professores aconteceu na dimensão da práxis, traremos o início da análise dos dados, guiada pelos significados locais que as expectativas com relação ao curso suscitaram. Em se tratando de uma pesquisa etnográfica, discutida por Clifford (1986, p. 98) como "uma performance delineada por histórias poderosas"10, que não podem ser vistas como meras descrições porque estão carregadas de afirmações adicionais morais, ideológicas e até cosmológicas, que representam a própria condição de significância (CLIFFORD, 1986), a análise é apresentada em primeira pessoa do singular, uma narrativa interpretativa construída a partir das vivências da pesquisadora e formadora em formação em momentos de escuta e diálogo com as professoras e professores participantes.

\section{"Eu chego a pensar até que a formação é uma farsa": as expectativas dos professores}

Pelas expectativas relatadas por escrito e também levantadas pelo grupo no engajamento discursivo do primeiro encontro, começo a fazer conexões com

\footnotetext{
${ }^{10}$ Texto original: "[...] a performance emplotted by powerful stories."
} 
acontecimentos não lineares vividos durante o curso, a fim de dar contornos locais a nossa história. Com essa intenção, inicio falando de algo que me chamou a atenção no relato de alguns professores ${ }^{11}$ : a vontade de ter contato com a pesquisa, com a academia, e suas impressões sobre a relação teoria e prática como uma reação às experiências de formação continuada que tiveram até então.

Esse desejo nos diz que os professores querem mais do que ser implementadores de teorias (CLARKE, 1994), ou técnicos que passam adiante conhecimentos prontos na sala de aula (PENNYCOOK, 1994). Muitos relatos orais e escritos dos participantes trouxeram a relação teoria e prática, e deixaram evidente essa preocupação em outros momentos do curso, em que questionam o porquê de muitas discussões não chegarem até eles, ou de se sentirem perdidos sem saber como buscar teorias que dialoguem com sua prática, o que pode ser exemplificado na vinheta narrativa ${ }^{12}$ em que descrevo a reação da professora Helena $^{13}$, a partir da seguinte nota de campo (NC):

\title{
Teorias em descompasso com a prática. (Helena, NC, E2/E3 ${ }^{14}$ ).
}

A seguir, descrevo e interpreto essa NC por meio de vinheta narrativa ${ }^{15}$, produzida no mesmo dia, após o encontro.

\begin{abstract}
Logo no segundo encontro (E2/E3), enquanto discutíamos pontos específicos dos textos lidos sobre o ensino de inglês como educação linguística, a professora Helena reage com indignação ao dizer que, enquanto fazia as leituras para o curso, pensava sobre como a teoria parece estar distante da prática: 'como eu não tinha acesso a isso aqui antes? Como que eu não sabia?'. Helena diz acreditar muito na teoria, sua reação e o seu sentimento com relação à distribuição do conhecimento e ao acesso à pesquisa trazem um misto de surpresa e indignação. Ao mesmo tempo em que sua voz traz indignação, a professora também problematiza sua prática: 'Nunca ninguém me falou disso aqui; por que só agora que eu já planejei e já fiz as aulas e já preparei tudo?' (Vinheta Narrativa, E2/E3).
\end{abstract}

Nessa manifestação, Helena demonstra ter pensado que seu planejamento poderia ter sido diferente se ela tivesse tido acesso aos textos anteriormente. Ainda é possível notar

\footnotetext{
11 Cf. nota de rodapé 1.

${ }^{12}$ A vinheta narrativa é um texto escrito a partir das impressões do vivido/observado no trabalho de campo, registradas, inicialmente, por meio de notas de campo ou de falas gravadas logo após a observação dos acontecimentos in loco.

${ }^{13}$ Os nomes utilizados na pesquisa são fictícios e foram escolhidos pelos próprios participantes. Isso não se aplica à professora-formadora, uma das autoras deste artigo, que utilizou seu nome real.

${ }^{14}$ A pedido dos professores, os encontros 2 e 3 foram realizados no mesmo dia, um sábado de trabalhos nos períodos matutino e vespertino. Por esse motivo, ao fazer referências a esse dia, utilizarei a descrição E2/E3.

${ }^{15}$ As vinhetas narrativas foram escritas a partir das notas de campo a fim de ampliar as percepções sobre determinado evento.
} 
um fluxo no percurso reflexivo da professora Helena quando, no quarto encontro (E4), ela dá indícios de que as reflexões do curso seriam importantes para a reconstrução de sua prática: "Eu queria voltar no tempo, no início do semestre e refazer a atividade com eles." (NC, E4). Ela se refere a um questionamento que sugeri que fizessem a seus alunos sobre o porquê aprender inglês. A atividade tinha como objetivo que alunos e professores pudessem repensar os objetivos da disciplina e problematizar as necessidades locais. Dada à impossibilidade de voltar no tempo, Helena sinaliza que pode ocorrer uma mudança em sua prática a partir de então ou, ao menos, explicita o desejo de discutir questões como essa com seus alunos. Nesse ponto, teoria e prática deixam de ter uma relação binária e começam a apresentar conexões entre o pensamento e a ação (LUCENA, 2015).

Entretanto, ainda no segundo encontro, a professora Cice também demonstra como se sente com relação ao que ela chama de "minha parte teórica":

[...] eu não sei, mas eu me sinto meio deslocada, eu me sinto distante, deve ser uma falha minha, eu acredito, porque a internet está aí e eu poderia muito bem pesquisar, mas eu não me sinto motivada para eu pesquisar a minha parte teórica (Professora Cice, NC, E2/E3).

$\mathrm{Na}$ preocupação de Cice está a dificuldade encontrada em buscar abordagens teóricas para o ensino de inglês, mesmo tendo recursos tecnológicos que facilitem essa busca. A professora diz não ter motivação, sentir-se deslocada e distante da "parte teórica", encarando a situação como uma falha pessoal. Porém, em minha análise, sua fala é representativa da solidão de professores em suas salas de aula, um sentimento que expõe a falta de oportunidades de interações com seus pares e com teorias de ensino de línguas. Mais adiante, a docente complementa seu pensamento inicial:

Cice: $\mathrm{E}$, além disso, como disse a Helena (referindo-se a uma fala anterior em que Helena argumenta que, além da dificuldade em acessar teorias, os professores estão sobrecarregados e sem tempo) a gente não tem tempo para se reunir, ainda tem isso. Até quando teve esse curso, é a nossa folga do sábado, né? É o dia de tudo, é o Dia D, na verdade, mas quando eu fiquei sabendo do curso [...] eu quis já, eu quis logo, porque nós não temos aqui... nós não temos essa possibilidade, essa chance de se encontrar (Professora Cice, NC, E2/E3).

Mesmo sem intenção, em alguns momentos, estávamos sustentando a separação entre teoria e prática, imaginando um limite que as separasse como dois lados da mesma moeda, mas que não acontecem ao mesmo tempo, e, ainda, mantendo o status de superioridade da teoria. Vale frisar que, apesar de o curso ter objetivos contrários a essa ideia, a crença de que o conhecimento teórico é necessário para a prática, e nunca o 
contrário, estava presente tanto na fala das professoras, quanto nas minhas como formadora.

\begin{abstract}
Ao ouvir as professoras e perceber essa diferenciação também na minha voz, preocupei-me em esclarecer para o grupo que a educação linguística fundamenta os documentos oficiais, mas também está no nosso dia a dia na sala de aula; salientei que o curso iria 'trazer coisas para serem discutidas', mas isso não significava que tudo seria bom para todas as realidades. Baseando-me no conceito freireano de práxis, tentei dizer que a teoria está na prática cotidiana do professor com seus alunos. Sendo assim, cada professor decidiria o que aproveitar a partir das reflexões que faríamos no curso, que funcionariam como um filtro para avaliar o que serviria ou não para suas realidades, com elementos que poderiam escolher manter e outros que poderiam mudar em suas práticas (Vinheta Narrativa, E2/E3).
\end{abstract}

Importa lembrar que a proposta do curso buscava a horizontalidade por meio da escuta e do diálogo (FREIRE; SHOR, 1987; FREIRE, 1991); para tanto, minha postura como formadora era a de interagir com as professoras e professores, estando aberta ao que tinham a dizer. Não me interessava falar "para" o professor, nem "pelo" professor ou "sobre" o professor, mas "com" o professor, desnaturalizando a ideia de conhecimento mais e menos importante durante aquela prática social. Garcez e Schlatter (2017, p. 33) acreditam que, se o intuito da formação de professores é "articular saberes técnicos e práticos, articulando-os entre si e relacionando-os com o vivido", insistir na cisão entre teoria e prática torna-se pouco produtivo. Para os autores,

A cisão também não é produtiva se entendemos formação como produto de diálogos em que oportunidades para formar podem ser construídas na convivência entre participantes mais e menos experientes nos mais diferentes aspectos que podem se tornar relevantes para a busca de práticas pedagógicas autorais. (GARCEZ; SCHLATTER, 2017, p. 33).

No entanto, ainda é necessário pensar como se dá a relação entre formadores e professores em formação, que, muitas vezes, alimenta a crença de que os primeiros detêm o conhecimento e, sendo assim, devem trazer um produto pronto para fornecer aos participantes da formação. Não posso encobrir o fato de que isso passou pela minha cabeça algumas vezes durante o curso, tendo em vista que, ao longo da minha carreira profissional, muitas coisas foram internalizadas, quer ouvindo os discursos de meus ex-professores, quer cedendo aos discursos de meus colegas. Como formadora, eu sentia a necessidade de trazer conhecimentos que conduziriam as discussões, mas, por outro lado, havia um esforço para não as limitar à minha experiência. $O$ interesse era pelo diálogo com o conhecimento local. 
Para tanto, as leituras prévias previstas na carga horária do curso serviram como uma provocação, um estímulo para que os professores refletissem e se posicionassem diante de questões intrínsecas ao ensino de língua inglesa, tais quais questões identitárias, interculturais e críticas, promovendo a problematização em meio a um processo de reflexividade. Pode-se dizer que o objetivo das leituras foi provocar rupturas pelas quais pudéssemos olhar de modo crítico para o ensino de inglês, sem ficarmos presos às teorias. O desafio era fugir de modelos de formação engessados, e nem um pouco situados, por meio da escuta como uma atitude relacional.

Assim, no primeiro encontro, os professores responderam por escrito às perguntas: "Why are you here?" e "What are your expectations?" (Action $\log ^{16}$, E1), pelas quais foi possível interpretar que eles se sentiram estimulados pelas leituras que haviam feito, como pode ser visto nas respostas das professoras Helena e Consuelo:

\begin{abstract}
Tenho as melhores expectativas em relação ao curso. Espero que o tempo seja realmente aproveitado para estudo e aprendizado. Depois da leitura dos textos propostos, sinto a necessidade de saber mais sobre a aplicação da teoria crítica nas aulas de inglês. (Professora Helena, Action Log, E1)

Abrir o meu pensamento e adquirir novos conhecimentos [...]. Através das leituras dos artigos, percebi que esse curso irá acrescentar muito em minha vida profissional e particular, assim adquirindo uma nova visão de mundo (Professora Consuelo, Action Log, E1).
\end{abstract}

Vejo que um aspecto importante da proposta do curso era a possibilidade de acessar questões que circulam na academia, mas que raramente chegam até os professores que estão trabalhando nas escolas. Como professora de inglês da Educação Básica, não me lembro de ter participado de discussões motivadas por leituras que me ajudassem a problematizar questões essenciais ao ensino de inglês. Ademais, a proposta buscava a ampliação da participação do conhecimento local dos professores, narrativas que colaboraram com as problematizações ao longo do curso. Nesse aspecto, os professores participantes também relataram que, em muitos cursos feitos ao longo da carreira, não tiveram a oportunidade de participar efetivamente, já que nessas ocasiões eram apenas ouvintes.

A preocupação com a própria formação também acompanhou os professores no terceiro encontro (E2/E3), o que pôde ser visto durante o engajamento discursivo sobre o texto "Se o inglês está no mundo, onde está o mundo nos materiais didáticos de inglês?", do

\footnotetext{
${ }^{16}$ Action Logs são "comentários escritos do aprendiz sobre atividades e eventos da sala de aula, suas atitudes, pensamentos, percepções, crenças e sentimentos sobre seu processo de aprendizagem" 16 (BARCELOS; MORAES, 2011, p. 192, tradução nossa). No texto original: "learners' written comments on activities and classroom events, their attitudes, thoughts, perceptions, beliefs and feelings about their learning process."
} 
professor Sávio Siqueira Pimentel, da Universidade Federal da Bahia (UFBA). Nele, o autor cita Canagarajah $(1993 ; 2006)$ como um estudioso cujas reflexões falam da necessidade de se partir da realidade local no ensino de línguas e enfatiza a demanda, que se apresenta cada vez mais frequente, de que "pesquisas e investigações sobre a aquisição de língua estrangeira sejam conduzidas pelos próprios professores” (SIQUEIRA, 2012, p. 340).

\begin{abstract}
Os professores têm que estar formados para aquilo. (Helena, NC, E4, grifo meu). Adianto que para a próxima semana os professores fariam uma investigação, uma pesquisa no livro didático que utilizavam em suas escolas, ou em outros livros do Programa Nacional do Livro Didático (PNLD), analisando a ocorrência de "histórias únicas ${ }^{17 "}$ presentes no material. Digo isso afirmando ser o que os autores [dos textos lidos] sugerem, acrescento que as pesquisas não precisariam ser uma tese de doutorado sobre a aula, mas que seriam pesquisas diárias, cotidianas, possíveis de serem incorporadas à prática docente, como esta que iriam fazer. Continuo, dizendo que o fato de estarmos reunidos facilitava a discussão sobre aspectos importantes para a realidade da sala de aula de línguas, que sozinhos, talvez, pudéssemos não parar para pensar nessas questões. Helena mostra-se apreensiva com o fato de o professor ter que ser pesquisador de sua prática: 'Tem que ser feito e conduzido pelos próprios professores! Mas os professores têm que estar formados para aquilo, têm que ter aquele conhecimento, porque, até então, tínhamos um pouco de conhecimento, mas agora [a partir do curso], quando formos analisar, vai ser diferente o nosso olhar. Eu já começo a olhar outras coisas, até as minhas aulas eu estou mudando'.

Fico feliz porque percebo que a professora está repensando sua prática. Já temos um dos elementos essenciais para a pesquisa: o questionamento (Vinheta Narrativa, após E4).
\end{abstract}

A apreensão de Helena está no fato de não se achar preparada para a pesquisa em sala de aula, por não ter tido essa formação. Em seguida, ela diz que a partir de sua participação no curso, nas problematizações sobre o ensino de inglês, está olhando para coisas que antes não olhava, e que isso já começa a se refletir em suas aulas. A professora Helena começa a se ver não mais como uma usuária de conhecimentos produzidos por outros (BORTONI-RICARDO, 2008), mas, através do olhar questionador para sua realidade, inicia um movimento de reconstrução do conhecimento.

Outros professores partilham da mesma preocupação sobre o processo de formação e, enquanto ouvem Helena falar, complementam sua ideia [alguns fazem movimentos afirmativos com a cabeça]. A professora Lolitta concorda com Helena e diz: 'a gente já olha [diferente], hoje, eu olhando uma prova... Nossa! Isso aqui está totalmente...', dando a entender que a prova não condizia com as leituras e discussões que estávamos fazendo sobre o ensino crítico de línguas estrangeiras. Enquanto presto atenção à fala da professora, complemento dizendo que isso é normal porque estávamos estudando e nos questionando o tempo todo; acrescento ainda que, se estamos em um curso de formação continuada, é para isso mesmo, para pensar sobre nossas práticas. Helena volta a se posicionar lembrando que antes [do curso], na escolha do livro didático (LD), ela dizia: 'ah, mas esse livro é ruim!' e, hoje, se questiona: 'Será que o livro é ruim, ou já está mais voltado

${ }^{17}$ Essa atividade foi proposta após problematizarmos o famoso discurso "The danger of a single story", de Chimamanda Ngozi Adichie (2009). 
para essa ideia [do LC] e nós ainda não estamos preparados?'. Ao ouvir a professora, eu acrescento mais um questionamento: 'será que ainda queremos que tenha aquele outro formato? [me referindo a livros cuja abordagem é estrutural e não sócio-discursiva]. Helena é enfática ao complementar sua fala: 'Sim, até porque nós não sabíamos, não tínhamos uma noção. Então, eu fico com medo quando falam que as coisas têm que ser produzidas pelo professor, meu Deus, então, eu tenho que saber!' (Vinheta Narrativa, após E4).

Por fim, a professora Helena ainda acrescenta que sai frustrada das formações porque, segundo ela, tudo o que está nos cursos é senso comum. O sentimento de que está sendo enganada deixa Helena desmotivada, tanto que ela diz ao colega Juan que gostaria de participar do curso ofertado pela instituição, mas esperava algum aprendizado, que esse curso fosse diferente daqueles que não acrescentam nada. Além disso, a docente parece preocupar-se com o que foi discutido por Siqueira (2012), pois ela diz sentir medo ao saber que "as coisas têm que ser produzidas pelo professor" e, ao mesmo tempo, traz uma carga de responsabilidade que a faz pensar: "meu Deus, então, eu tenho que saber!" Nesse momento, a conversa entre os professores faz emergir significados relativos a como se sentem diante de teorias: ao mesmo tempo que a desejam, temem por pensarem não estar preparados para o que dizem os teóricos, reforçando a dicotomia teoria-prática, em que os professores assumem a carga de ter que pôr a teoria em prática. Há também a ideia de que estavam ali apenas para aprender, o que motivou o diálogo abaixo:

\footnotetext{
Estevan: E como a gente necessita disso, quando eu recebi o convite [para participar do curso], volto a falar nisso, mesmo não estando em turma regular, eu sinto essa necessidade! Qual é a linha de pensamento agora? O que já surgiu? Por que as coisas mudam em dois, três anos, assim! Meu Deus!

Helena: Eu falei para o Juan Pablo: 'eu quero ir lá, mas que a gente vá aprender [...]' Estevan: É, e eu gosto assim!

Helena: Eu tô cansada de formações que a gente teve e não aprende nada, e não acrescenta [...].

Estevan: E não aproveita nada [...].

Helena: Então, um momento assim, em que a gente está comentando [sobre cursos de formação continuada], eu chego a pensar até que a formação é uma farsa (NC, E4).
}

A meu ver, a distância que a formação continuada pode estar tomando da sala de aula, ao afastar-se dos desafios reais que permeiam as relações escolares nas contingências da prática docente (GARCEZ, 2013) podem levar os professores a pensarem dessa forma. Conforme observado nas falas acima, pode-se dizer que, dialogando com o texto de Siqueira (2012), os professores começam a criar sentidos em reposta à ideia do professor como pesquisador de sua prática e percebem a necessidade de "olhar de forma diferente", adaptar ou mudar algumas práticas e, ainda, mais convictamente, falam da 
necessidade de ter acesso ao conhecimento necessário para serem pesquisadores e produtores de conhecimento.

No entanto, Garcez (2013, p. 217) afirma que a necessidade de teorização acontece devido à reflexão pregressa, ou seja, deve acontecer a partir da prática, privilegiando "a perspectiva e o protagonismo dos atores, no nosso caso dos agentes educacionais." $\mathrm{Na}$ mesma linha, Nóvoa (2001, s/p), em entrevista concedida a Paola Gentile entende que, mesmo as universidades tendo um papel importante no plano teórico e metodológico, "todo esse conhecimento só terá eficácia se o professor conseguir inseri-lo em sua dinâmica pessoal e articulá-lo com seu processo de desenvolvimento". Daí a importância de que a formação continuada contribua com a compreensão da prática docente de maneira situada, ouvindo os professores para conhecer as contingências da escola, a fim de ajudá-los a lidar com as complexidades que se apresentam (GARCEZ, 2013).

Helena ainda cita como exemplo para a problemática da falta de acesso ao conhecimento teórico o processo de escolha do livro do Programa Nacional do Livro Didático (PNLD). Para ela, os livros do programa eram ruins porque ela os avaliava com foco em critérios que privilegiavam a abordagem estrutural. Mas hoje, ao refletir sobre o fato de que os livros didáticos trazem implícitas teorias de ensino-aprendizagem de línguas, questiona se estava preparada para avaliar e escolher o livro didático. Mesmo que a preocupação da professora seja a de não conhecer as teorias, o que se percebe é um movimento de reflexão pregressa (GARCEZ, 2013), que acontece da prática (escolher o livro didático) para a teoria (o letramento crítico).

No fim desse encontro, em que mobilizaram conhecimentos relativos à necessidade de uma formação continuada que faça sentido diante dos desafios de ensinar inglês, os professores voltaram a falar sobre a temática, dessa vez referindo-se à experiência de formação pela qual estavam passando:

Enquanto conversávamos sobre a programação do próximo encontro, Cice olha para mim e diz: 'olha, prof., vou dizer outra coisa, a gente vem cansado, mas eu não quero deixar de vir, porque eu vejo assim, que além de eu aprender, eu ainda posso me avaliar. E, assim, tenho saído bem chateada comigo, decepcionada comigo!' Eu digo que não era o objetivo que eles saíssem do curso chateados e a professora se explica: 'não, mas eu vejo assim, no sentido de 'puxa, como eu preciso! Preciso demais.' Os outros professores também participam:

Lolitta: Precisa de mudança, né?

Estevan: Falei para a Helena, estava falando a mesma coisa para ela, a gente se auto percebe: 'eu tenho que melhorar, eu tenho que estudar mais, eu tenho que melhorar a minha prática'. Já tá causando isso, já tá causando... já está atingindo o objetivo (Vinheta Narrativa, após E4). 
A percepção de Cice mostra que as problematizações do curso até aquele momento estavam sendo válidas para ela, do mesmo modo que para Estevan estar participando do curso causou a autopercepção, como ele disse, de que havia necessidade de melhorar sua prática. Isso, conforme Garcez e Schlatter (2017, p. 13), reforça o entendimento "de que a formação de professores se dá em atividades de autorreflexão na prática e mediante vivência de experiências situadas de docência e reflexão coletiva sobre experiências vividas".

Movida pelo diálogo com os professores, terminei aquele encontro dizendo:

Lediane: Então, eu fico feliz porque é um dos objetivos do curso que a gente reflita sobre as nossas práticas, né? Só não quero que vocês pensem que o curso é para dizer o que é certo e o que é errado, tá gente? [...] (NC, E4).

Eu não queria estar ali para defender posições, nem para julgar as práticas dos professores ou determinar como elas deveriam ser. Mesmo tendo consciência de que todo aprendizado implica um movimento, sempre fica a pergunta: para onde? Por isso, meu intuito era trabalhar para que as impressões e experiências fossem compartilhadas.

Até aqui, as interpretações trouxeram à tona necessidades de formação que circularam pelas vozes das professoras e professores a fim de refletir, localmente, sobre o que precisam, querem e, sobretudo, o que esperavam do curso de formação continuada que se iniciava, de onde sentidos e sentimentos com relação às contingências da profissão começavam a emergir.

\section{Considerações finais}

Como vimos, os primeiros acontecimentos do curso mostraram reações com relação aos modelos de cursos de formação continuada, considerados até mesmo uma farsa tendo em vista a não contribuição para com a prática docente, o que muitas vezes durante o curso emergiu em sentimentos de insegurança, reforçando a sensação de estar perdido em um emaranhado de teorias e documentos oficiais. Relacionando-se a isso, foi possível observar os anseios das professoras e professores participantes por discussões sobre o ensino de inglês junto a seus pares.

Salientamos que o curso de formação continuada, campo desta pesquisa, não teve a pretensão de formatar ou desformatar professores (JORDÃO; MARTINEZ; HALU, 2011), nem de consertar, remendar, reparar ou mesmo transformar. Exigir dos professores uma mudança seria concordar com a concepção de formação continuada como um produto e 
não como processo. Também não descartamos a possibilidade de que haja mudança ou transformação, o que pode ocorrer sob a ótica da reflexão. Porém, entendemos que a formação do professor é um processo subjetivo e contínuo, em que cada um está em um lugar no processo de desenvolvimento profissional e, consequentemente, tem objetivos diferentes para estar lá. Portanto, a partir da concepção de formação continuada assumida nesta pesquisa, baseada na constante busca pela reflexão e pela escuta como fundamento do diálogo (FREIRE, 2011a), refletiu na postura interpretativo-responsiva assumida pela pesquisadora, professora e formadora em formação durante a realização deste estudo.

Por esses motivos, ao invés de buscar elementos comprobatórios da transformação da prática docente, acreditamos ser mais oportuno olhar para as desestabilizações causadas pelas problematizações do curso como possibilidades de ressignificação dos conhecimentos locais das professoras e dos professores participantes.

\section{Referências}

ADICHIE, Chimamanda N. The danger of a single story. Palestra proferida no TEDGlobal. Youtube, jul. 2009. Disponível em: Disponível em: https://cutt.ly/0Ir23JF. Acesso em: 08 de ago. 2018.

BAGNO, M.; RANGEL, E. Tarefas da educação lingüística no Brasil. Revista Brasileira de Lingüística Aplicada, Belo Horizonte, v. 5, n. 1, p. 63-82, 2005.

BARCELOS, Ana Maria F.; MORAES, Rafael B. Beliefs and emotions in action longs of future English teachers. In: MASTRELLA-DE-ANDRADE, Mariana Rosa (ed.). Afetividade e emoções no ensino/aprendizagem de línguas: Múltiplos olhares. Campinas: Pontes Editores, 2011. p. 191-214.

BORTONI-RICARDO, Stella Maris. O professor pesquisador: introdução à pesquisa qualitativa. São Paulo: Parábola Editorial, 2008.

CANAGARAJAH, Suresh. Reconstructing local knowledge, reconfiguring language studies. In: CANAGARAJAH, Suresh (Ed.). Reclaiming the local in language policy and practice. Mahwah: Erlbaum, 2005.

CLARKE, Mark A. The Dysfunctions of the Theory/Practice Discourse. TESOL Quarterly, v. 28, n.1, p. 9-26, 1994.

CLIFFORD, James. On ethnographic allegory. In: CLIFFORD, J.; MARCUS, G. Writing culture: the poetics and politics of ethnography. Berkeley and Los Angeles: University of California Press, 1986. p. 98-121.

CORBETT, J. An Intercultural Approach to English Language Teaching. Clevedon: Multilingual Matters Ltd, 2003. 
COX, Maria Inês P.; ASSIS-PETERSON, Ana Antônia. de. O professor de inglês: entre a alienação e a emancipação. Linguagem \& Ensino. Revista do Curso de Mestrado em Letras. Universidade Católica de Pelotas, v. 4, n. 1, p. 11-36, 2001.

ERICKSON, Frederick. What makes school ethnography "ethnographic"? Anthropology and Education Quarterly, v. 15, n.1, p. 51-66, 1984.

FREIRE, Paulo. Pedagogia da Autonomia: saberes necessários à prática educativa. 43. ed. São Paulo: Paz e Terra, 2011a.

FREIRE, Paulo. Pedagogia do oprimido. 50. ed. São Paulo: Paz e Terra, 2011b.

FREIRE, Paulo. A Educação na Cidade. São Paulo: Cortez, 1991.

FREIRE, Paulo.; SHOR, I. Medo e ousadia: o cotidiano do professor. 3. ed. Rio de Janeiro: Paz e Terra, 1987.

GARCEZ, Pedro M. [Conversa com] Pedro de Moraes Garcez. In: SILVA, K.A.; ARAGÃO, R. (org.). Conversas com formadores de professores de línguas. Campinas, SP: Pontes, 2013. p. $215-228$.

GARCEZ, Pedro M. Educação linguística como conceito para a formação de profissionais de Língua Estrangeira. In: MASELLO, L. (Org.) Portugués lengua segunda y extranjera en Uruguay: Actas del Primeiro Encontro de Português Língua Estrangeira do Uruguai. Montevidéu, Faculdad de Humanidades y Ciencias de la Educación/Comisión Sectorial de Investigación Científica, 2008. p. 51-57.

GARCEZ, Pedro. M.; SCHLATTER, Margarete. Professores-autores-formadores: princípios e experiências para a formação de profissionais de educação linguística. In: MATEUS, E.; TONELLI, J. R. A. (Org.). Diálogos (im)pertinentes entre formação de professores e aprendizagem de língua. Londrina: Editora Edgard Blücher Ltda, 2017. p. 13-36. Disponível em: <https://cutt.ly/DkMC2o3>. Acesso em: 1 nov. 2019.

HAWKINS, Margaret; NORTON, Bonny. Critical language teacher education, In: BURNS, A.; RICHARDS, J. (Eds.). Cambridge guide to second language teacher education.

Cambridge: Cambridge University Press. 2009. p. 30-39. Disponível em:

<https://cutt.ly/9kOKtnt>. Acesso em: 12 out. 2019.

JORDÃO, Clarissa M. [Entrevista cedida a] Francisco Carlos Fogaça, Denise Hibarino e Denise Kluge. Revista X, Curitiba, v. 12, n. 1, p. 187-194, 2017.

JORDÃO, Clarissa M. O ensino de línguas estrangeiras: de código a discurso. In: KARWOSKI, A. M.; BONI, V. (Org.). Tendências contemporâneas no ensino de inglês. União da Vitória: Kaygangue, 2006. p. 26-32.

JORDÃO, Clarissa M.; MARTINEZ, J.Z.; HALU, R.C. (Org.) Formação "Desformatada": práticas com professores de língua inglesa. Campinas: Pontes, 2011.

KUMARAVADIVELU, Bala. Critical language pedagogy: a postmethod perspective on English language teaching. World Englishes, Oxford, v. 22, n. 4, p. 539-550, 2003. 
LUCENA, Maria Inêz P. Práticas de linguagem na realidade da sala de aula: contribuições da pesquisa de cunho etnográfico em Linguística Aplicada. DELTA, n. 31 Especial, p. 67-95, 2015.

MANFÉ DE SOUZA, Lediane. Por entre práticas em movimento: um estudo etnográfico com professores de inglês em formação continuada. 2014. Dissertação (Mestrado em Estudos de Linguagem) - Instituto de Linguagens, Universidade Federal de Mato Grosso, Cuiabá, 2014.

MENEZES DE SOUZA, Lynn Mário T. Para uma redefinição de Letramento Crítico: conflito e produção de significação. In: MACIEL, R. F.; ARAÚJO, V. de A. (Org.). Formação de professores de línguas: ampliando perspectivas. Jundiaí: Paco Editorial, 2011. p. 128-140.

MOITA LOPES, Luiz Paulo. Inglês no mundo contemporâneo: Ampliando oportunidades sociais por meio da educação (texto-base). In: SIMPÓSIO DA TESOL INTERNATIONAL RESEARCH FOUNDATION. 2005, São Paulo. Anais [...]. São Paulo: Centro Brasileiro Britânico, 2005.

MONTE MOR, W. Letramentos críticos e expansão de perspectivas: diálogo sobre práticas. In: JORDÃO, C. M.; MARTINEZ, J. Z.; MONTE MÓR, W. (Orgs.). Letramentos em Prática na Formação Inicial de Professores de Inglês.1 ed. Campinas, SP: Pontes Editores, 2018a, v.1, p. 315-335.

MONTE MÓR, Walkyria. Sobre rupturas e expansão na visão de mundo: seguindo as pegadas e os rastros da formação crítica. In: PESSOA, R. R.; SILVESTRE, V. P. V.; MONTE MÓR, W. (Org.). Perspectivas críticas de educação linguística no Brasil: trajetórias e práticas de professoras(es) universitárias(os) de inglês. São Paulo: Pá de Palavra, 2018b. p. 263-276.

MONTE MÓR, W. Critical literacies in the Brazilian university and in elementary/secondary schools: the dialectics between the global and the local. In: MACIEL, R. F.; ARAUJO, V. A. (org.) Formação de professores de línguas: ampliando perspectivas. Jundiaí: Paco Editorial, 2011. p. 307-318.

MONTE MÓR, W. Foreign languages teaching, education and the new literacies studies: expanding views. In: GONÇALVES, G. R.; ALMEIDA, S. R. G.; PAIVA, V. L. M. de O. e; RODRIGUES-JUNIOR, A. S. (Org.). New Challenges in Language and Literature. Belo Horizonte: FALE/UFMG, 2009. p. 177-189

NORTON, Bonny. Identity, Literacy, and English-Language Teaching. TESL Canada Journal/Revue TESL du Canada, n. 1, v. 28, Winter. 2010. Disponível em: <https://cutt.ly/Jkmbgrf>. Acesso em: 15 out. 2019.

NÓVOA, Antônio. Professor se forma na escola. [Entrevista cedida a] Paola Gentile. In: Revista Nova Escola, n. 142, mai. 2001. Disponível em: <https://cutt.ly/xkMNnbi>. Acesso em: 11 dez. 2019.

PENNYCOOK, Alastair. Uma linguística aplicada transgressiva. In: MOITA LOPES, L. P. (Org.). Por uma linguística aplicada indisciplinar. São Paulo: Parábola Editorial, 2006. p.67-84. 
PENNYCOOK, Alastair. The Cultural Politics of English as an International Language. London: Longman, 1994.

RAJAGOPALAN, Kanavillil. Repensar o papel da linguística aplicada. In: MOITA LOPES, L. P. (Org.) Por uma linguística aplicada indisciplinar. São Paulo: Parábola Editorial, 2006. p. $149-168$.

RAJAGOPALAN, Kanavillii. Por uma linguística crítica: linguagem, identidade e questão ética. São Paulo: Parábola Editorial, 2003.

SANTIAGO, Maria Eliete. E.; BATISTA NETO, José. Formação de professores em Paulo Freire: uma filosofia como jeito de ser-estar e fazer pedagógicos. Revista e-curriculum, São Paulo, v. 7, n. 3, dez. 2011. Edição especial de aniversário de Paulo Freire. Disponível em: <https://cutt.ly/hk9o79k>. Acesso em: 10 set. 2019.

SIQUEIRA, Domingos Sávio $P$. Se o inglês está no mundo, onde está o mundo nos materiais didáticos de inglês? In: SCHEYERL, D.; SIQUEIRA, S. (Org.). Materiais didáticos para o ensino de línguas na contemporaneidade: contestações e proposições. Salvador: EDUFBA, 2012. p. 311-354.

\section{Agradecimentos}

Nossos agradecimentos são para as professoras e os professores da escola pública participantes deste estudo, representantes de tantos outros que pelo Brasil afora abrem suas salas de aula e seus espaços de formação para o diálogo com a universidade.

Recebido em: 21/06/2021

Aceito em: 29/09/2021 